\title{
A systematic review and appraisal of methods of developing and validating lifestyle cardiovascular disease risk factors questionnaires
}

\author{
Odunaiya Nse ${ }^{1,2}$, Louw Quinette ${ }^{1}$, Ogah Okechukwu ${ }^{3}$
}

1. Division of Physiotherapy, Stellenbosch University, RSA

2. Department of Physiotherapy, University of Ibadan, Nigeria.

3. Department of Internal medicine, University College Hospital, Ibadan, Nigeria

\begin{abstract}
Background: Well developed and validated lifestyle cardiovascular disease (CVD) risk factors questionnaires is the key to obtaining accurate information to enable planning of CVD prevention program which is a necessity in developing countries. We conducted this review to assess methods and processes used for development and content validation of lifestyle CVD risk factors questionnaires and possibly develop an evidence based guideline for development and content validation of lifestyle CVD risk factors questionnaires.

Materials/methods: Relevant databases at the Stellenbosch University library were searched for studies conducted between 2008 and 2012, in English language and among humans. Using the following databases; pubmed, cinahl, psyc info and proquest. Search terms used were CVD risk factors, questionnaires, smoking, alcohol, physical activity and diet.

Results: Methods identified for development of lifestyle CVD risk factors were; review of literature either systematic or traditional, involvement of expert and /or target population using focus group discussion/interview, clinical experience of authors and deductive reasoning of authors. For validation, methods used were; the involvement of expert panel, the use of target population and factor analysis.
\end{abstract}

Conclusion: Combination of methods produces questionnaires with good content validity and other psychometric properties which we consider good.

Keywords: systematic review, lifestyle cardiovascular disease, risk factors questionnaires

DOI: http://dx.doi.org/10.4314/ahs.v15i3.30

Cite as: Nse O, Quinette L, Okechukwu O. A systematic review and appraisal of methods of developing and validating lifestyle cardiovascular disease risk factors questionnaires. Afri Health Sci. 2015;15(3):931-40. doi: http://dx.doi.org/10.4314/ahs. $v 15 i 3.30$

\section{Introduction}

The most common cause of mortality in the western world is cardiovascular disease (CVD), and its prevention and management is national health priority in many developed countries. CVD causes twice as many deaths as HIV, malaria and tuberculosis combined in developing countries ${ }^{1}$. The overall burden of CVD is on the increase in both developed and developing countries. Between 1990 and 2020, coronary heart disease alone is anticipated to increase by 120 percent in women and 137 percent in men in developing countries ${ }^{2}$ The increase in CVD burden in developing countries is largely the result of an increase in the prevalence of risk fac-

\section{Corresponding author: \\ Odunaiya Nse \\ Division of Physiotherapy, \\ Stellenbosch University, RSA; \\ Department of Physiotherapy, \\ University of Ibadan, Nigeria. \\ Email: nselaw2000@gmail.com}

tors especially lifestyle risk factors and a relative lack of access to good interventions. As a result, age-adjusted death rates from stroke and ischemic heart disease are increasing in some developing regions, and a relatively younger population is afflicted by CVD. This has led to an increased number of deaths in the working-age population ${ }^{3}$.

Identification, intensive management and prevention of risk factors for CVD are important especially in developing countries which lack facilities and personnel for sophisticated acute and critical care. Before implementing intervention and prevention programs it is pertinent to assess and ascertain CVD risk factors. This however, can only be achieved through well developed and validated CVD risk factors measures.

Various questionnaires have been developed to assess lifestyle CVD risk factors. Many questionnaires assess one CVD risk factor such as smoking ${ }^{4}$, alcohol ${ }^{5}$, physical activity ${ }^{6}$ and nutrition/diet ${ }^{7}$. Numerous reports are in literature of several questionnaires developed for 
various population to assess lifestyle CVD risk factors ${ }^{8}$, ${ }^{9,10}$. Questionnaires of composite lifestyle CVD risk factors are sparse. Few of such are youth risk behavior surveillance system by $\mathrm{CDC}^{10}$ and youth health behavior by Gilmer et $\mathrm{al}^{11}$. The importance of valid questionnaires to assess CVD risk factors include investigating prevalence of CVD risk factors, discriminating between those with and without the problems and monitoring interventions. The need for such questionnaires to have good psychometric properties cannot be overemphasized and the process of development is the key to developing good or bad questionnaires. These psychometric properties include, content validity, reliability, construct validity, criterion validity etc

A measure is valid if it accurately describes the underlying phenomenon or disease ${ }^{12,13,14}$. Criterion validity is the demonstration of the accuracy of an assessment compared with a particular standard, the criterion, using correlation coefficients, concordance, or percentage agreement ${ }^{14}$. Construct validity is demonstrated by examining the relations among a newly created test and other tests to show that the new test measures the same "construct." This conceptual approach is most useful when a definite criterion for comparison does not exist, as in the measurement of intelligence or anxiety. In the case of construct validity mentioned above, correlation coefficients or other regression methods are used to demonstrate construct validity ${ }^{14,15}$.

Content validation relies on expert opinions and reviews of the literature. According to Dziedzic et $\mathrm{al}^{14}$, Statistical methods are generally not helpful, and an assertion of content validity may simply state that the items in the scale are reasonable variables that adequately measure a specific condition. Content validity therefore examines the extent to which the concepts of interest are comprehensively represented by the items in the questionnaire ${ }^{16,17}$ It is advocated that in order for the content validity of a questionnaire to be adequately examined, authors should provide a clear description of the various aspects regarding the development of a questionnaire which are the measurement aim of the questionnaire, whether the questionnaire is discriminative, evaluative, or predictive? This question is necessary for the readers to be able to rate the quality of a questionnaire $^{18}$. Since questionnaires from one population may not be easily transposed to another population for many reasons such as language and culture, there is constant need to develop questionnaires for different populations or at least adapt and validate the existing questionnaire to suit another population. The process of developing or validating the questionnaires for content by many authors is not usually explicit in many published articles.

Few reviews have assessed the psychometric properties of self report with the view to giving guideline on how to identify valid self report using their psychometric properties $^{20}$. To date, we are not aware of systematic reviews that have assessed methods for development and validation of lifestyle CVD risk factors questionnaires. The outcome of this review, we hope will be very useful for developing countries which are presently facing the increasing burden of CVD due to lifestyle changes.

This review is part of a larger project. The review was conducted to identify methods for development and content validation of lifestyle CVD risk factors questionnaire which are sparsely reported in literature and to possibly develop an evidence based guideline for development and content validation of Lifestyle CVD risk factors questionnaire. This paper reports findings from studies that developed and validated (for content) lifestyle CVD risk factors such as smoking, drinking alcohol, physical activity and diet. The specific objectives of the review were:

To identify various methods used in developing Lifestyle CVD risk factors questionnaires

To identify methods used in content validation of such questionnaires

To assess other psychometric properties in relation to the methods of development and content validation of selected questionnaires

\section{Methodology}

Relevant databases at the Stellenbosch University library were searched for studies conducted from 2008 to 2012, in English language and among humans using the following databases; pubmed, cinahl, psyc info and proquest. Search terms used were CVD risk factors, questionnaires, smoking, alcohol, physical activity and diet.

Eligibility criteria: Studies considering development, content validation and scale refinement were used. Development of questionnaire was defined as the process of constructing a new questionnaire or reducing the length of the existing questionnaire thereby making it 
shorter to become a short form of the questionnaire or adapting the existing questionnaire in another population. Validation studies were included if they considered the process of content validation. We did not consider reliability study and other psychometric properties of a questionnaire as this are commonly reported in the literature. Lifestyle CVD risk factors considered were smoking, alcohol, physical activity and nutrition/ diet. Studies were excluded if they did not include detail of development or validation process. Books, book chapters, theses, and dissertations were excluded. Inclusion decisions were made by one reviewer, with reference to a second reviewer in the case of uncertainty.

\section{Quality assessment}

Quality assessment of selected studies was undertaken using the Terwee criteria for assessment of validation studies. Studies were rated positive, negative or indeterminate. Positive rating referred to studies of higher quality. Terwee ${ }^{17}$ Criteria for assessment of validation studies was used with regard to development process and content validation process. Positive scores showed the development process and validation process were detailed and involved expert and target population. Study quality was assessed independently by 1 reviewer and a second reviewer involved in case of uncertainty.

Table 1: Quality criteria for measurement properties of health status questionnaire

\begin{tabular}{|c|c|c|}
\hline Property & Definition & Quality criteria \\
\hline Content validity & $\begin{array}{c}\text { The extent to which the } \\
\text { domain of } \\
\text { interest is } \\
\text { comprehensively } \\
\text { sampled by } \\
\text { the items in the } \\
\text { questionnaire }\end{array}$ & $\begin{array}{c}\text { + A clear description is provided of the } \\
\text { measurement aim, the target population, } \\
\text { the concepts that are being measured, and } \\
\text { the item selection AND target population } \\
\text { and (investigators OR experts) were } \\
\text { involved in item selection; } \\
\text { ? A clear description of above-mentioned } \\
\text { aspects is lacking OR only target } \\
\text { population involved OR doubtful design or } \\
\text { method }\end{array}$ \\
& $\begin{array}{c}\text { No targetpopulation involvement; } \\
\text { 0 No information found on target } \\
\text { population involvement }\end{array}$ \\
& \multicolumn{2}{|c}{} \\
\end{tabular}

\section{Data extraction.}

One reviewer independently extracted data and any uncertainty resolved by second reviewer.

Information extracted was; type of lifestyle CVD risk factor, country of development of the questionnaire, population for which the questionnaire was developed, name of the questionnaire, development process, type of validation and content validation process.

Analysis; qualitative analysis was done. Data could not be pooled together being qualitative in nature. The findings are presented in narrative form

\section{Result}

24,335 studies were found, 308 studies were selected by title, 24,027 studies were rejected because the title had no bearing with the objectives of the review. 52 studies were selected by abstract and 52 full length articles were read. 16 articles were selected. Figure 1 shows the selected studies. 16 studies met the inclusion criteria. They considered lifestyle CVD risk factors such as smoking, alcohol, physical activity, they considered development or validation or producing a short version/ adapted version. 


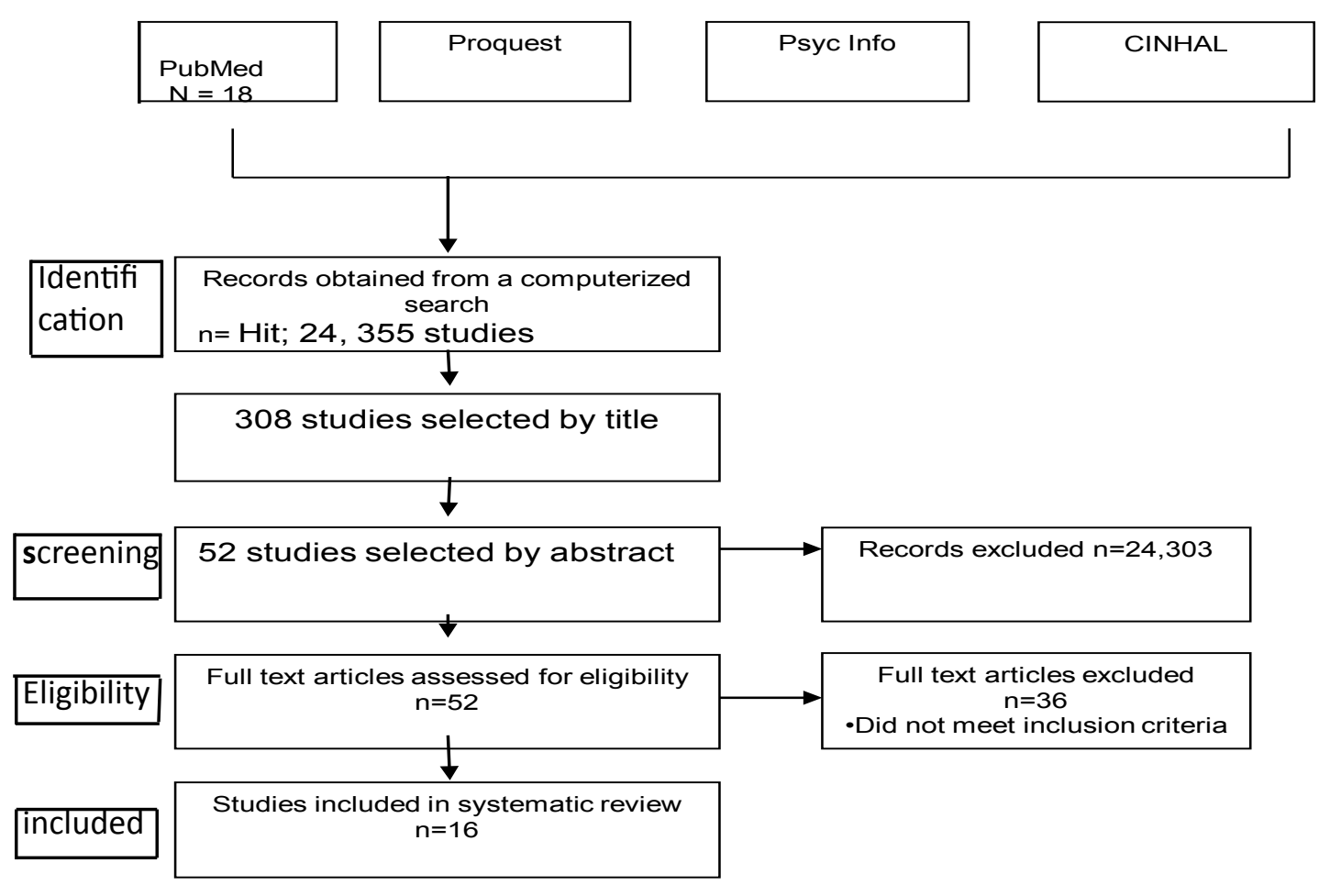

Abbreviations: $\mathrm{n}=$ total number

Figure 1: PRISMA flow diagram of literature search

\section{General description of the studies}

Sixteen out of the fifty two full length article read had details of either/both development and content validation processes. Of the 16 studies selected, 5 lifestyle CVD risk factors questionnaires were developed and validated in the United States of America, 2 in the United Kingdom, 3 from Japan, 2 from Brazil, 1 from Germany, 1 from Italy, 1 from Switzerland and 1 from 5 European counties. There was no questionnaire from Africa that discussed development and content valida- tion processes. 5 of the questionnaires were for adolescents population, 3 for children and 7 for adults.

\section{Methods of development of CVD risk factors questionnaire}

Seven methods of development of selected lifestyle CVD risk factors questionnaires were identified. Literature review was used in development of four questionnaires and expert panel was also used in development of four questionnaires and others utilized in-depth interview, clinical experience as shown in table 2. 
Table 2 Methods of development of CVD risk factors questionnaires

\begin{tabular}{|l|l|}
\hline Methods of development & No of studies \\
\hline Review of literature & 4 \\
\hline Focus group discussion & 1 \\
\hline In-depth interview & 1 \\
\hline Expert panel/ consultant & 4 \\
\hline Clinical experience & 1 \\
\hline Deductive reasoning by authors & 1 \\
\hline Target population & 3 \\
\hline
\end{tabular}

Summarily, out of the 16 studies included in this review,7 studies had combination of 2-3 of the processes, 4 studies were not clear on their development process but were clear on their validation process, 3 studies did not include the development process and 1 study had only the authors in the development process.

Content validation process utilized include expert panel in four studies, target population was utilized in four studies and factor analysis in three studies as shown in table 3

Table 3: Methods of content validation of CVD risk factors questionnaire

\begin{tabular}{|l|l|}
\hline Methods of content validation & No of studies \\
\hline Expert panel & 4 \\
\hline Target population & 4 \\
\hline Factor analysis & 3 \\
\hline
\end{tabular}

Summarily for content validation, two studies were not clear about their validation process and six studies did not involve either experts or target population
Table 4 shows the various questionnaires identified, the countries where the questionnaires were developed and the process of development and validation 
Table 4 shows the various questionnaires identified, the countries where the questionnaires were developed and the process of development and validation

\begin{tabular}{|c|c|c|c|c|c|c|}
\hline Study & Date & Country & Name of questionnaire & Target pop & Devt proc & Vali process sco \\
\hline Nicolai et al & & 2010 & The Comprehensive Alcohol Expectancy Questionnaire & Adults & $x$ & Factor anal + \\
\hline $\begin{array}{l}\text { Kuntsche and } \\
\text { Kuntsche }\end{array}$ & 2009 & Switzerland & Drinking motive questionnaire- revised short form & Adolescents & $\begin{array}{l}\text { Review, original questionnaire, } \\
\text { adolescents }\end{array}$ & Factor ana + \\
\hline $\begin{array}{l}\text { Caseli and } \\
\text { Spada }\end{array}$ & 2011 & Italy & Desire thinking questionnaire & Adolescents & $\begin{array}{l}\text { Structured interview, authors clinical } \\
\text { experience, deductions }\end{array}$ & $\begin{array}{l}\text { Participants + } \\
\text { Confirmatory } \\
\text { factor anal }+\end{array}$ \\
\hline Takachi et al & 2011 & Japan & Food frequency questionnaire & Adults & Authors & $x$ \\
\hline $\begin{array}{l}\text { Henderson et } \\
\text { al }\end{array}$ & 2011 & US & $\begin{array}{l}\text { Measure to assess the child -care nutrition and physical } \\
\text { environment }\end{array}$ & Children & $\begin{array}{l}\text { Review of existing measures, child } \\
\text { care expert, consultants }\end{array}$ & $\begin{array}{l}\text { Feedback from pilot } \\
+\end{array}$ \\
\hline Araujo etal & 2010 & Brazil & Food frequency questionnaire & Adolescents & Food record & ?? ? \\
\hline John etal & 2009 & UK & $\begin{array}{l}\text { Heart disease knowledge questionnaire for people with } \\
\text { rheumatoid arthritis }\end{array}$ & Adults & \begin{tabular}{|l} 
Original questionnaire and focus \\
group discussion \\
\end{tabular} & Expert panel + \\
\hline Watanebe et al & 2008 & Japan & FFQW82 & Adolescents & $\begin{array}{l}\text { Not clear } \\
--\end{array}$ & $\begin{array}{lll} & ? \\
X x x & ? \\
\end{array}$ \\
\hline Jahal et al & 2011 & US & $\begin{array}{l}\text { Compensatory eating and behaviors in response to alcohol } \\
\text { consumption scale (CEBRACS) }\end{array}$ & Adults & & $x x x$ \\
\hline Smith et al & 2010 & US & Brief Wisconsin inventory of smoking dependence motive & Adults & Not clear & $x \times x$ \\
\hline Okuda et al & 2011 & Japan & Physical activity questionnaire for Japanese students & Adolescents & Review, experts, target population & $\begin{array}{l}\text { Experts, target population } \\
+\end{array}$ \\
\hline Decker & 2011 & US & $\begin{array}{l}\text { Questionnaire of parental efficacy for enacting healthy } \\
\text { lifestyle in their children }\end{array}$ & $\begin{array}{l}\text { Children - proxy } \\
\text { questionnaire }\end{array}$ & Not clear & Xxx $\quad ?$ \\
\hline Michel et al & 2008 & $\begin{array}{l}\text { Five Europian } \\
\text { countries; } \\
\text { germany, } \\
\text { Austria, } \\
\text { netherland } \\
\end{array}$ & $\begin{array}{l}\text { Questionnaire to assess dietary habits of children 5-13 years } \\
\text { old }\end{array}$ & Children & Not clear & $x X X$ \\
\hline $\begin{array}{l}\text { Rubeinstein et } \\
\text { al }\end{array}$ & 2011 & US & $\begin{array}{l}\text { New Physical activity questionnaire for a sedentary } \\
\text { population }\end{array}$ & Adults & $\begin{array}{l}\text { Indepth interview, experts, target } \\
\text { population }\end{array}$ & Expert, target population \\
\hline Leite et al & 2011 & US & $\begin{array}{l}\text { Psychosocial treatment expectation } \\
\text { questionnaire (PTEO) for alcohol problems }\end{array}$ & Adults & Review, expert & $\begin{array}{l}\text { Expert, target population } \\
+\end{array}$ \\
\hline Kingston et al & 2011 & Brazil & Composite measure of problem behaviour & Adults & Review, Expert, target population & $\begin{array}{l}\text { Expert panel, Target } \\
\text { population }\end{array}$ \\
\hline
\end{tabular}




\section{Discussion}

Studies on development and content validation processes of health questionnaires especially CVD risk factors questionnaires are sparse. Many published studies on questionnaire lack detail of development process and content validation process. There was no study from Africa on development and validation of lifestyle CVD risk factors questionnaires. This could be because CVD and non communicable diseases are not given attention in Africa. Most African countries are still battling with infectious diseases and malaria though, CVD epidemic is looming in Africa. Terwee ${ }^{17}$ stated that a high quality questionnaire should involve the target population or expert in development. According to Odunaiya et $\mathrm{al}^{36}$ , in places/ environment where the target population are not knowledgeable about the disease condition being examined, developers of such health questionnaires would need to rely more on expert panel than the target population for content validation of the questionnaire. This could be the situation in some African countries especially in the rural areas.

Development process identified in this review consists of review of literature. This method was a preliminary process in development of 4 questionnaires in the review. 3 out of the 4 questionnaires have good psychometric properties. Review of literature has many advantages especially if it is systematic. One of such advantages is identification of similar questionnaires. This may mean that authors may not design new questionnaire or at the most the authors may only need to adapt the questionnaire to suit the environment where the questionnaire would be utilized. Where there is need to design a new questionnaire, justification of such will be obvious. Apart from the afore mentioned reasons, in designing the new questionnaire, items may be selected/ adapted from existing questionnaire as deemed relevant. Questionnaires that were developed starting with literature review had high content validity because they covered relevant content areas. However, it is important to select questionnaires that have good psychometric properties from where items can be generated for the design of the new questionnaire. From this review we propose that authors should start the process of development of CVD risk factors questionnaires and other health questionnaires with systematic or extensive literature review but other methods should be included as using only literature review could pose some limitations. Questionnaires that were developed with only literature review had some limitation such as short comings of the previous questionnaire. The implication is that, in reviewing literature, the intending authors should try to improve on the psychometric properties of the existing questionnaire when designing a new questionnaire.

Experts; Development of 3 questionnaires involved the experts. These experts were people in the field where such questionnaires were being developed. The experts were consultants or researchers. The inputs of experts make these questionnaire have good content validity. This is particularly useful in the areas where target population may not be knowledgeable enough about the disease $^{36}$. According to Terwee et $\mathrm{al}^{17}$, involvement of expert and or target population gives a questionnaire a positive rating.

Focus group indepth/interviews; Focus group discussion/ indepth interview involves the target population or the experts. The population that the questionnaire will be used to collect information. Focus group discussion usually involve a number of people 6-8 with a moderator who has a focus guide to ask necessary information needed in the questionnaire. Indepth interview identifies key people in the target population to get information which is deemed necessary in the questionnaire. According to Terwee ${ }^{17}$, process of development involving target population should be rated positive. This implies that the questionnaire is likely to have good content validity. Involvement of target population especially in the development of questionnaire for common problems like behavioural problems will help in including items very important to the population

Clinical experience of authors; Clinical experience was used in the development of one questionnaire. As good as clinical experience is, it is not sufficient to be used in questionnaire development. Even though a clinician is an expert, one person's experience will not substitute for a panel of experts and the target population. This questionnaire did not show good psychometric properties. According to Terwee ${ }^{17}$ criteria this method will not be rated positive because it does not involve experts or target population

Inductive reasoning by authors; Inductive reasoning usually comes from experience. This will not suffice for lifestyle CVD risk factors questionnaire development as in the case of using author's experience. 
Combination of methods; Combination of methods implies that questionnaire development is done in stages. Few questionnaire developed using combination of methods were quite rigorous. Literature review was done, then experts / target population were involved. CVD questionnaires developed with combination of methods shows good psychometric properties in other validity measures ${ }^{8,9,33}$. This is probably due to refinement following each stage of development. We opine that for questionnaires to have good to excellent content validity, it has to go through rigorous development process which include literature review, preferably systematic, to identify relevant questionnaire, experts and target population inputs are very necessary. This has to be explicit before other psychometric testing

\section{Validation methods}

Experts: 4 studies involved experts in their validation process. This method according to Terwee ${ }^{17}$ gives a questionnaire a positive rating. Experts have broad knowledge of the condition and know questions that are appropriate. Asking valid questions is so important in order to take the appropriate measure. However, involvement of target population apart from the expert further validates the questionnaire as questions will be answered by target population and not experts. The Experts could use technical words and still answer right but the target population may not get the question right. Questionnaire is not necessarily valid for target population because the experts have said so especially when the language is not appropriate.

Target population: five studies involved the target population in their validation processes. According to Terwee 17, questionnaire which involved target population has positive rating for validation. Involvement of target population ensures that there are no ambiguous questions and that the questions are understood by the people who will complete the questionnaire. This is so crucial for content validity. We propose that experts and target population be involved in the development and validation processes.

Factor analysis: Factor analysis is a statistical method of validation. 3 studies used factor analysis for validation in this review. 2 of the studies were to reduce the length of existing questionnaires and 1 was a newly developed questionnaire. According to Terwee 17, questionnaire using factor analysis should be rated positive.
Combination of methods: In this review, 4 studies combine 2-3 methods of validation experts/ target population and factor analysis. According to Terwee ${ }^{17}$, this method of validation process should be given a positive rating. Validation process using combined methods are rigorous and produce high quality questionnaire in content.

Conclusion: This systematic review was conducted to identify methods of development and validating lifestyle CVD risk factors questionnaires. We identified 4 methods of development; literature review, experts, focus group/ in-depth interview, (using target population) inductive reasoning and combination of 2 or more of these methods.

Validation methods identified were; experts, target population and factor analysis.

Many studies are not detailed about development and validation process of questionnaires which is of primary importance if we must have high quality questionnaire. Lifestyle CVD risk factors questionnaires that involved experts and target population had good content validity and other good psychometric properties.

\section{Recommendation and proposed guidelines for de- velopment and validation of lifestyle CVD risk fac- tors questionnaires;}

We recommend that the following stages should be followed in designing or developing lifestyle/health questionnaire

Systematic review of literature to identify existing questionnaires which could be used in constructing a new questionnaire.

Items generation, selection or aggregation should be done

Meeting with experts in the fields for their input

Target population input should be sought

Validation process should involve experts. There should be a meeting until experts reach consensus after which it should be pretested among the target population. In reducing the length of existing questionnaire, factor analysis should be done.

\section{Acknowledgement}

This study was funded by African Population and Health Research center in Collaboration with IDRC and FORD FOUNDATION. 


\section{References}

1. Lopez AD, Matthers CD (2006) Alan D. Lopez, Colin

D. Mathers, Majid Ezzati, Dean T. Jamison, and Christopher J. L. Murray.

2. leeders (2004).

3. Gaziano TA (2007); Reducing the burden of Cardiovascular diseases in the developing world. Health Aff (Millwood) 26 (1) 13-24

4. Sun P, Unger J Band Sussman S (2005): A new measure of smoking initiation and progression among adolescents. American Journal of Health behavior 29 (1): 3-11.

5. Saunders JB, Aasland OG, Babor TF, de la Feunte JR and Grant M (1993) Development of Alcohol Use Disorder Identification Test(AUDIT); WHO Collaborative project on early detection of persons with Harmful Alcohol Consumption- II, Addiction 88,791-804.

6. Kowalski KC, Crocker PRE and Kowalski NP (1997). Convergent validity of physical activity questionnaire for adolescents. Paeditric exercise Science, 9, 342-352.

7. Johnson B, Hackett A, Roundfield M and Coufopoulos S (2001); An investigation of the validity and reliability of a food intake questionnaire. J Hum Nutr Dietet, 14457-465.

8. Kingston J,Clarke S, Ritchie T and Remington B(2011) Developing and validating the composite measure of problem behavior. Journal of clinical psychology, 67(7) 736751.

9. Knutche E and Knutche S (2009); Development and validation of drinking motive questionnaire- revised short form (DMQ-RSF). Journal of clinical child and adolescent psychology, 38;83-87.

10. Center for disease control (CDC) 2005. Youth risk behavior surveillance system.

11. Gilmer M J, Speck B J, Bradley C, Harrel J S and Belyea M, (1996): The Youth health survey: reliability and validity of an instrument for assessing cardiovascular health habits in adolescents. The Journal of School Health 66 (3):106.

12. Hallin P, Sullivan M,Kreuter M (2000); Spinal cord injury and quality of life measures; A review of instrument psychometric quality. Spinal cord, 38; 509-23.

13. Haywood KL, Garrat AM, Fit Z Patric R (2005); Quality of life in older people. Strutured reviewed of geriatric self assessed health instrument. Qual life res. 14, 1651-68.

14. Dziedzic KS, Thomas E, Hey EM (2005): A systematic search and critical review of measures of disability for use in population survey of hand Osteoarthritis. Osteoarthritis cartilage 13;1-12.
15. Mcdowel I and Jenkinson C (1996) Development standard and for health measures. J Health Serv Res Policy 1;238-46.

16. Guyatt GH, Freeny DH, Patric DL (1993); Measuring health related quality of life. Ann intern med, 118; 622-9.

17. Terwee CB, Bot SDM, Deboer MR, et al (2007) Quality criteria were proposed for measurement properties of Health status questionnaire. Journal of clinical epidemiology, 60, 34-42.

18. Kirschner B and Guyatt G (1985); Methodological framework for assessing health indices. $J$ chronic dis 38; 27-36.

19. Wilson IB and Cleary PD (1995); Linking clinical variables with health related quality of life. $J A M A, 273$; $59-65$.

20. Gasglow R E, Ory M G, Klesges L M, Maribel Cifuentes, Fernald D H and Green L A(2005): Practical and relevant self-report measures of patients' health behaviors for primary care research. Annals of Family Medicine 3: 73-81.

21. Nicolai J, Dammel R, and Moshgan M (2010); The comprehensive Alcohol Expectancy Questionnaire; confirmatory factor analysis, scale refinement and further validation. Journal of Personality Assessment 92; 5; 400-409.

22. Caselli G and Spada MM (2011). The Desire Thinking Questionnaire.; development and psychometric properties. Addictive behaviours, 36; 1061-1067.

23. Takachi R, Ishihara J, Iwasaki M et al (2011); Validity of a self-administered food frequency questionnaire for middle aged urban cancer screenees; comparison with 4 day weighed dietary records. J of Epidemiol 21 (6) 447-458.

24. Henderson KE, Grode GM, Middleton AE, Kenney EL, Falbe J, Schwartz MB (2011); Validity of a measure to assess the child nutrition and physical activity environment. J Am Diet Assoc 111; 13061313.

25. Araujo MC, Yokoo EM, Pereira RA (2010); Validation and calibration of semiquantitative food frequency questionnaire designed for adolescents. J of Am Diet Assoc 110;1170-1177.

26. John H, Treharne GJ, Hale ED, Panoulas VF, Carrol D, Kitas GD (2009); Development and initial validation of Heart Disease Knowledge Questionnaire for People with Rheumatoid Arthritis. Patient Education and Counselling. 77;136-143.

27. Watanabe M, Yamaoka K, Yokotsuka M, Adachi M, Tango T (2011); Validity and reproducibility of the 
FFQ (FFQW82) for dietary assessment in female adolescents. Public Health Nutrition, 14 (2) 297-305.

28. Rahal CJ, Bryant JB, Darkes J, Menzel JE, Thompson K (2012); Development and validation of the compensatory eating behavior in response to alcohol consumption scale (CEBRACS). Eating behaviours, 13; 83-87. 29. Smith SS, Piper ME, Bolt DM, Fiore MC, et al (2010); Development of the brief Wisconsin Inventory of smoking dependence motives. Nicotine and Tobacco Research, 12 (5) 489-499.

30. Okuda M, Yoshitake N, Tankuka S et al (2011); Validity and reliability of Physical Activity Questionnaire for Japanese Students. Paediatrics International, 53; 956 963.

31. Decker JW (2011); Initial development and testing of a questionnaire of parental efficacy for enacting healthy lifestyle in their children. Journal of Specialists in Paeditric Nursing, 17;147-158.

32. Michels KB, Waser M, Ary E, Roselud H et al
(2008); Validation of questionnaire to assess dietary habits among 5-13 year old school children of Farmers and Arthroposophic Families. Journal of Nutritional and Environmental Medicine, 17 (3) 157- 168.

33. Rubeinstein JH, Morgenstern H, Kellenberg J et al (2011); Validation of a new Physical activity questionnaire for a sedentary population. Dig Dis Sa, 56; 26782687.

34. Leite JC, Seminotti N, Freitas PF, Drachcer M (2011); The Psychosocial Treatment Expectation Questionnaire (PTEQ) for Alcohol Problems. European Journal of Psychological assessment, 27 (4) 228-236.

35. Kingston J, Clarke S, Ritchie J, Remington B (2011); Developing and validating CompositeMeasure of Problem Behaviour. Journal of Clinical Psychology.

36. Odunaiya NA, Louw QA, Grimmer- sommers K, Ogah OS (2014); Development, initial content validation and reliability of Nigerian composite CVD risk factors questionnaire for adolescents, African Health Sciences. 